\title{
LATRINE SITE SELECTION OF RACCOON DOGS IN A HILLY AREA IN NORTH-EASTERN JAPAN
}

\author{
Kazuma Watanabe, Nami Kumagai and Masayuki U. Saito*
}

Faculty of Agriculture, Yamagata University, 1-23 Wakaba-machi, Tsuruoka 997-8555, Japan

*Corresponding author. Email: saito.ume@gmail.com

\author{
Article history \\ Received: 5 June 2021; \\ accepted: 16 September 2021
}

\section{Keywords:}

Carnivore; camera trap; communication; defecation; Nyctereutes procyonoides; topography; vegetation

\begin{abstract}
We evaluated the environment types of raccoon dog latrine sites in the hilly areas of north-eastern Japan. We conducted a route census in the spring and autumn of 2020 to record the latrine sites and analysed the relationship between the presence or absence of latrine sites and environmental factors, namely, topographic position index (TPI), slope, normalised difference vegetation index (NDVI), and vegetation type for each season. To investigate the space use of raccoon dogs, we also conducted camera trapping from July to November 2020 along the spring survey route. We analysed the relationship between the occurrence frequency of raccoon dogs and TPI, slope angle, NDVI, and vegetation type. The analysis showed that latrine sites tended to be located at sites with a high TPI (topography closer to the ridge) in both seasons. However, the occurrence of latrine sites in broadleaf forests was significantly higher in autumn. The frequency of raccoon dogs, based on camera-trap footage, was significantly higher at sites with gentle slopes; although the environment and space used by raccoon dogs at these sites differed. Raccoon dogs possibly select visually and olfactorily conspicuous sites on the ridge as latrine sites to facilitate odour dispersal. In addition, broadleaf forests in autumn are considered important feeding grounds for raccoon dogs, suggesting that the latrine sites were formed near foraging sites.
\end{abstract}

\section{INTRODUCTION}

A latrine site is a specific place where animals repeatedly defecate; many carnivores form such sites (Buesching and Jordan 2019). The site is not just a place for excretion but has several functions. Buesching and Jordan (2019) noted that hypotheses about the function of latrine sites fall into five categories: defence and claiming of resources, provision of information about individuals such as reproductive status and social affiliation, landmarks for topographic information, avoidance of parasites by using places not preferred by parasites as defecation sites, and predatorprey interactions such as assistance in avoidance of predators, and finding prey species. Due to these functions, latrine site location is critical. For example, the relatively large latrine site of the golden jackal (Canis aureus) is selected at the boundaries of territories to defend and claim resources (Macdonald 1979). For North American river otters (Lontra canadensis), the latrine site is located at a slightly elevated position that is visually and olfactorily conspicuous in order to facilitate communication with other individuals (Depue and David 2010; Swimley et al. 1998). Thus, the spatially biased distribution of latrine sites is evidently related to their function. Conversely, this spatial bias may provide clues for inferring the function of the latrine sites.

The raccoon dog (Nyctereutes procyonoides) is a medium-sized canid of the order Carnivora, which is widely distributed in various environments of Japan (Saeki 2015; Saito and Koike 2013, 2015). Raccoon dogs, like many other carnivorous orders, are known to form latrine sites (Ikeda 1984). They can identify and memorise the odour of other individuals through their faeces (Yamamoto 1984; Yoshida and Saito 2021). Therefore, the latrine sites of raccoon dogs are used to discriminate between individuals from within and outside their social group (Ikeda 1984; Yamamoto 1984). It has also been pointed out that raccoon dogs may mark important sites by forming latrine sites near their foraging areas (Ikeda 1984). For raccoon dogs, which primarily exhibit nocturnal activity patterns (Watabe and Saito 2021a,b; Saeki 2015), the latrine site is an important tool for communication at night when visibility is poor. Studies have reported that latrine sites of raccoon dogs are often located on ridges, loose saddles, and gently sloping microtopographies (Kishimoto 2000; Miyata et al. 1989; Yashiki 1987; Ikeda 1984). It has been found that raccoon dog latrine sites are often located in broadleaf forests, places with sparse understory vegetation, and open grasslands (Kishimoto 2000; Sekiya 1998; Yashiki 1987). However, the locations of raccoon dog latrine sites are generally based on observation reports, and no studies have quantitatively evaluated the selectivity of these locations.

Previous studies have shown that some carnivores select visually and olfactorily conspicuous sites (e.g., Depue and David 2010; Espírito-Santo et al. 2007; Swimley et 
al. 1998; Macdonald 1979). It is possible that ridges and rocky tops are chosen because they may be easier to spot by other individuals and spread scent readily (Swimley et al. 1998). Furthermore, raccoon dogs are opportunistic omnivores (Saeki 2015) and primarily feed on fruits, invertebrates including insects, and small vertebrates (Akihito et al. 2016; Hirasawa et al. 2006; Sasaki and Kawabata 1994). Plant matter is eaten throughout the year, whereas animal matter, such as insects, is eaten from summer to autumn (Saeki 2015). If latrine sites function as markers for foraging sites (Ikeda 1984), their location can be related to vegetation that provides food resources such as fruits and insects for raccoon dogs. Therefore, it is important to evaluate both topography and vegetation to understand latrine site location selection of raccoon dogs.

In this study, we aimed to quantitatively evaluate the type of environment in which the latrine sites of raccoon dogs were selected in hilly areas with multiple topographies and vegetation types. We hypothesised that latrine sites are 1) selectively formed at visually and olfactorily conspicuous sites such as ridges and 2) formed near vegetation that provides important food resources, such as fruits, for raccoon dogs. To verify these hypotheses, we used a route census to analyse the environment in which latrine sites were formed. However, we realised that it would not be possible to determine whether raccoon dogs actively select such environments to form latrine sites or if they form latrine sites in areas that are frequently used. Therefore, we analysed whether the environment determined to be conducive to the formation of latrine sites matches the space use patterns of raccoon dogs as assessed by camera traps. If the environment in which the latrine site is located differs from the space use of raccoon dogs, we can assume that raccoon dogs selectively created the latrine sites in environments in which they can perform odour communication function better. The environmental characteristics of the latrine sites of raccoon dogs will provide useful information on the function of latrine sites.

\section{METHODS}

\section{Study area}

We conducted a field survey around Mt. Takadate in Tsuruoka City, north-eastern Japan $\left(38^{\circ} 45^{\prime} \mathrm{N}, 139^{\circ} 44^{\prime} \mathrm{E}\right.$; Figure 1a). The study area was approximately $5 \mathrm{~km}^{2}$. The study area was hilly, with elevations ranging from 10 to $273 \mathrm{~m}$, and it included ridges and valleys. The region belongs to the cool temperate zone, with an average annual temperature of $12.5^{\circ} \mathrm{C}$ and annual precipitation of $2097.5 \mathrm{~mm}$ (Japan Meteorological Agency 2021). There were two large ponds in the study area, and much of the land was covered by forest. The forest consisted of approximately $70 \%$ broadleaf trees such as Fagus crenata, Quercus crispula, and Zelkova serrata, and approximately $30 \%$ coniferous trees such as Cryptomeria japonica and Pinus densiflora. There were footpaths through the forest.

\section{Field survey}

We searched for latrine sites along a survey route in the study area. To account for seasonal differences in the appearance of latrine sites, we conducted surveys in spring (10 March - 24 April 2020) and autumn (25 October 26 November 2020). We set the survey route to include multiple topographies and vegetation types. We recorded the positional information using a GPS device (eTrex20x, Garmin International, Inc., Kansas, USA) when we found a latrine site on the survey route. We defined a latrine site as a site where two or more pieces of relatively new faeces were recorded (Palomares 1993).

To investigate the space use patterns of raccoon dogs, we conducted a camera trap survey from 20 July to 25 November 2020. We randomly created ten sites along the survey route used in the spring survey using the "Create Random Points" tool in ArcMap 10.7 (Esri Inc., California, USA) and set up an infrared sensor camera (STC-G42NG, STEALTH CAM, Texas, USA) for 15 to 23 days. We conducted this seven times and surveyed 70 camera traps. The camera was installed approximately $1 \mathrm{~m}$ above the ground. We took three photographs with one detection with a shooting interval of $1 \mathrm{~min}$. Individuals photographed within $30 \mathrm{~min}$ were treated as a single event (O'Brien et al. 2003).

\section{Environmental factors}

We used the topographic position index (TPI) and slope angle $\left(^{\circ}\right)$ as topographic factors. The TPI is defined as the difference between the elevation value in a cell and the average elevation value of the circle around the cell. A negative TPI value indicates a topography closer to a valley, whereas a positive value indicates a topography closer to a ridge. A TPI of approximately zero indicates a flat or sloped area (not a ridge or valley). In this study, we calculated the TPI with a radius of $50 \mathrm{~m}$. The elevation values for calculating the TPI and slope angle were obtained from a numerical elevation model with a spatial resolution (cell size) of $5 \mathrm{~m}$ based on an aerial laser survey published by the Geospatial Information Authority of Japan (2020). Because this elevation data had some missing values, we used the inverse distance weighting method with the "IDW" tool in ArcMap 10.7 to interpolate the values.

We used the normalised difference vegetation index (NDVI) and forest type to describe vegetation in the study area. For the calculation of NDVI, we used LANDSAT8 satellite images, with cloud cover less than 
$10 \%$, obtained from LandBrowser (National Institute of Advanced Industrial Science and Technology 2021). For the environmental assessment of the latrine site, we used satellite images taken on 4 April 2020 for spring and on 16 October 2015 for autumn. In the analysis of space use, we used satellite images from 27 September 2014. For the forest type, we used broadleaf forests based on a previous study (Sekiya 1998). We used a 1:25,000 scale vegetation map from the sixth and seventh national surveys of the natural environment published by the Ministry of the Environment (2020) to identify forest types in the study area. We divided the study sites into

(a)

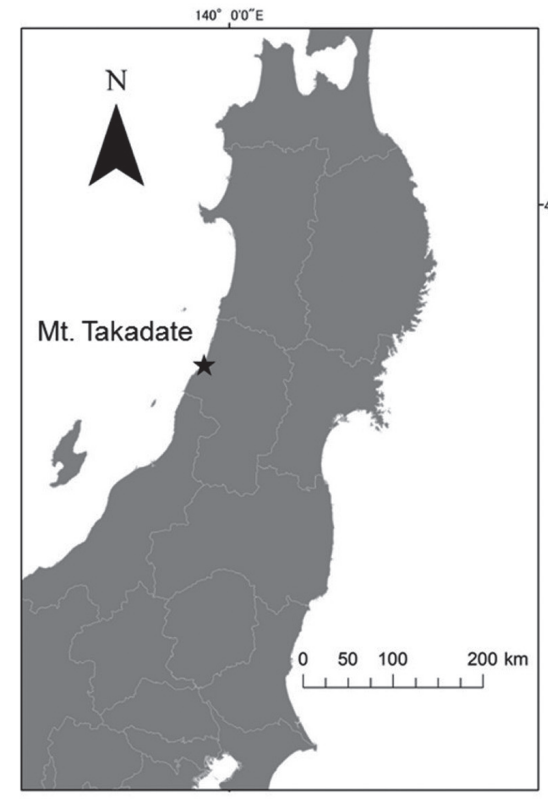

(c)

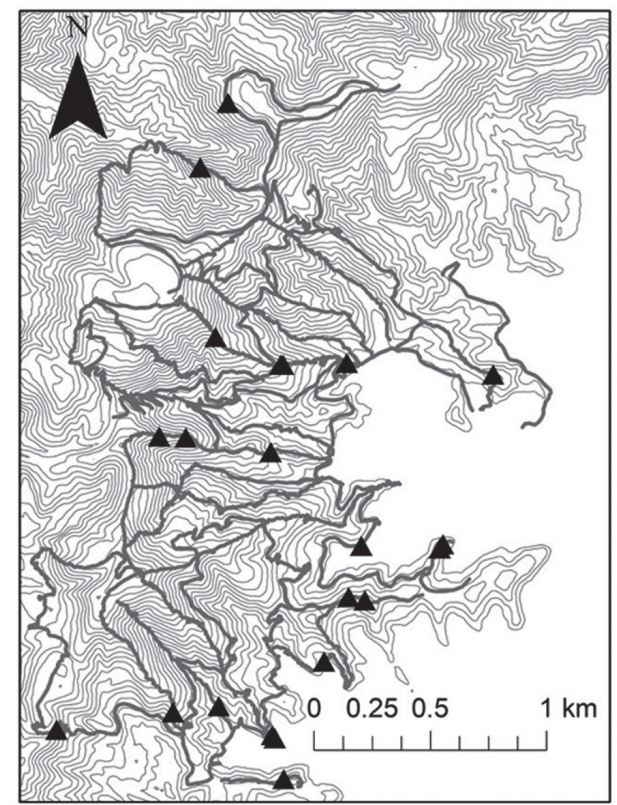

broadleaf forests (1) and other vegetation (0) based on the vegetation map.

\section{Data analysis}

We constructed the "bagging GLM" (Osawa et al. 2000), a statistical analysis method that combines a generalised linear model (GLM) and bootstrap aggregation to explain the presence or absence of the latrine site based on the environmental factors, for the spring and autumn data. In this study, we used the latrine site found in the route survey as the presence and 2000

(b)

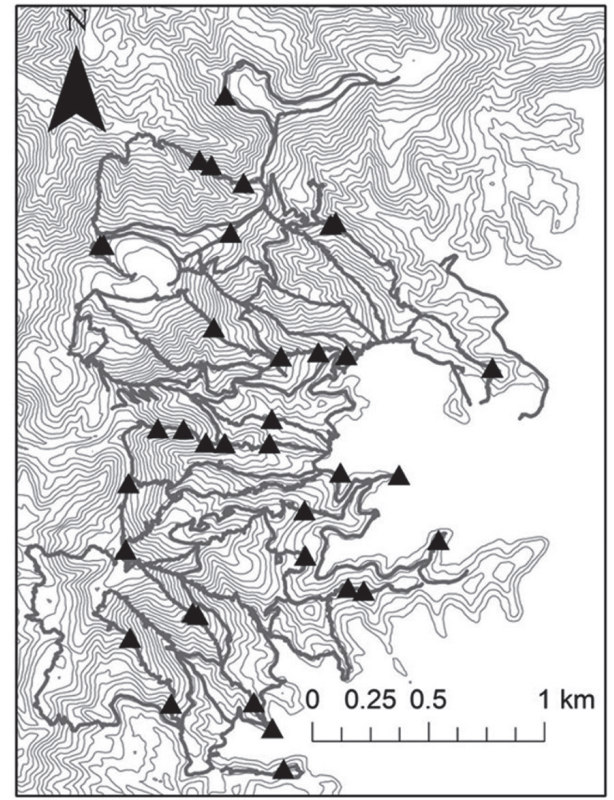

(d)

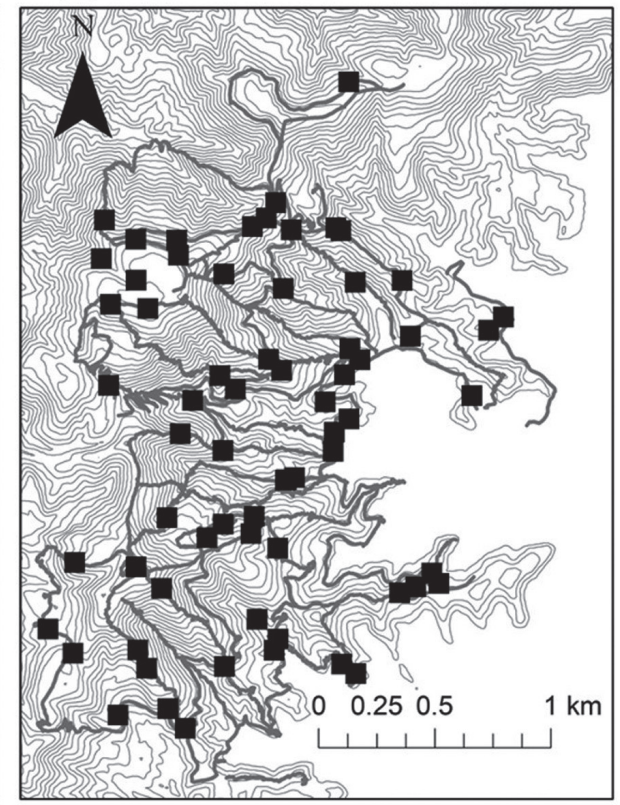

Figure 1. Location of the study area in north-eastern Japan (a), the survey route and latrine sites found by survey ( $\boldsymbol{\Delta}$ ) in spring (b) and autumn (c) around Mt. Takadate, and camera trapping sites ( $\mathbf{a})$ in the spring survey route (d). 
randomly generated points on the route as the absence. The environmental factors used as explanatory variables were TPI, slope angle, NDVI, and broadleaf forest category. The presence or absence of a latrine site was assumed to follow a binomial distribution, and logit was used as the link function. To check for multicollinearity in the model for each season, we calculated the Pearson product-moment correlation coefficient $r$ and compared it across all variables. The results of this analysis indicated that the correlation coefficients between all variables in each model were low $(|r|<0.7)$, and thus we assumed that multicollinearity was not an issue (Dormann et al. 2013). The iteration number for the bagging GLM was set to 5000, and the mean and 95\% confidence interval of the regression coefficient were calculated from the values obtained in each iteration. The relative importance of the variables was compared using the absolute values of the standardised regression coefficients. The statistical significance of the variables was tested by checking whether the $95 \%$ confidence interval crossed zero. If the confidence interval did not cross zero, then the variable was significant.

We also constructed a GLM to analyse the spatial use patterns of raccoon dogs in the study area. We used the same explanatory variables as in the latrine site model described earlier. The occurrence frequency of raccoon dogs was assumed to follow a negative binomial distribution, and the log was used as the link function. We used the logarithm of the camera days in the offset term because of the different durations of each camera trap. Correlation coefficients between variables were checked in the same way as in the model for the latrine site, and we confirmed that multicollinearity was not an issue. The relative importance of the variables was compared using the absolute values of the standardised regression coefficients. The statistical significance of the variables was tested using the Wald test.

To conduct all analyses, we used the cor and glmfunctions in the stats package and the glm.nb function in the MASS package in R 4.0.2 (R Core Team 2020).

\section{RESULTS}

\section{Latrine sites}

Overall, the distance covered in our survey route was $40.8 \mathrm{~km}$ in spring and $35.9 \mathrm{~km}$ in autumn, during which 36 and 22 latrine sites were recorded, respectively (Figure 1b, c).

In the bagging GLM model output for spring, the TPI had a significantly positive effect (Table 1), indicating that the occurrence probability of latrine sites in spring was higher at sites with a higher TPI. No significant differences were detected in slope angle, NDVI, and broadleaf forest (Table 1). In the bagging GLM model output for autumn, significant differences were detected for the TPI and broadleaf forests, and the regression coefficients were both positive (Table 1). This indicated that the occurrence probability of latrine sites in autumn was high in sites with a high TPI and broadleaf forests. The relative importance of these two variables based on standardised regression coefficients was almost the same (Table 1). No significant differences were detected in slope angle and NDVI (Table 1).

Table 1. Parameter estimates of bagging generalised linear models (Bagging GLMs) for the presence or absence of raccoon dog latrines in spring and autumn. TPI is the topographic position index and NDVI is the normalised difference vegetation index.

\begin{tabular}{|l|c|c|c|}
\hline \multirow{2}{*}{ Variable } & \multirow{2}{*}{$\begin{array}{c}\text { Standardised } \\
\text { regression } \\
\text { coefficient }\end{array}$} & \multicolumn{2}{|c|}{$95 \%$ confidence interval } \\
\cline { 3 - 4 } & Lower & Upper \\
\hline Spring & -0.73 & -0.98 & -0.50 \\
\hline Intercept & 1.33 & 0.73 & 2.05 \\
\hline TPI & -0.45 & -0.96 & 0.05 \\
\hline Slope & -0.16 & -0.61 & 0.19 \\
\hline NDVI & 0.03 & -0.42 & 0.43 \\
\hline Broadleaf forest & \multicolumn{3}{|}{} \\
\hline Autumn & -0.98 & -1.37 & -0.58 \\
\hline Intercept & 1.11 & 0.54 & 1.80 \\
\hline TPI & -0.59 & -1.48 & 0.24 \\
\hline Slope & 0.54 & -0.26 & 1.43 \\
\hline NDVI & 1.10 & 0.19 & 1.88 \\
\hline Broadleaf forest &
\end{tabular}

\section{Space use patterns}

We used 67 of the 70 sites for our analysis, excluding three sites with inadequate installation methods (Figure 1d). Of the 67 sites, raccoon dogs were photographed at 18 sites, and the total number of occurrences of raccoon dogs was 49 . The total number of camera days was 1,214 .

The results of the GLM indicated that the slope angle was a significant variable $(p<0.05)$, and the regression coefficient was negative (Table 2). This indicated that the occurrence frequency of raccoon dogs was higher on gentle slopes. No significant differences were detected for TPI, NDVI, and broadleaf forest categories (Table 2).

\section{DISCUSSION}

The bagging GLM model results revealed that raccoon dogs tended to select their latrine sites in environments with a higher TPI, indicating preference for topography 
Table 2. Parameter estimates of a generalised linear model (GLM) for the occurrence frequency of raccoon dogs determined by camera traps. TPI is the topographic position index and NDVI is the normalised difference vegetation index.

\begin{tabular}{|l|c|c|c|c|c|}
\hline \multirow{2}{*}{ Variable } & \multirow{2}{*}{ Standardised regression coefficient } & \multirow{2}{*}{ Standard error } & \multicolumn{2}{c|}{$95 \%$ confidence interval } & \multirow{2}{*}{$p$-value } \\
\cline { 3 - 6 } & & & Lower & Upper & $<0.01$ \\
\hline Intercept & -3.54 & 0.32 & -4.16 & -2.91 & 0.13 \\
\hline TPI & 0.47 & 0.31 & -0.14 & 1.09 & 0.01 \\
\hline Slope & -0.86 & 0.34 & -1.53 & -0.19 & 0.20 \\
\hline NDVI & -0.40 & 0.31 & -1.00 & 0.21 & 0.28 \\
\hline Broadleaf forest & -0.33 & 0.30 & -0.91 & 0.26 & $<$ \\
\hline
\end{tabular}

that is closer to the ridge, in both spring and autumn seasons (Table 1). The results of the autumn route survey also showed that the occurrence probability of latrine sites was high in broadleaf forests, in addition to ridges (Table 1). Both topographic and vegetation factors were related to the distribution of latrine sites, although there were seasonal differences. The results of camera traps and GLM analysis showed that raccoon dogs avoided steep slopes but showed no particular preference for other environments (Table 2). Our results suggest that the environment in which the latrine sites were located and the space use of raccoon dogs differed and that raccoon dogs selected ridges and broadleaf forests to form latrine sites. In summary, the hypotheses of this study were supported by the data. The characteristics of the environment in which the latrine sites were formed supported the findings of observation reports (Kishimoto 2000; Sekiya 1998; Miyata et al. 1989; Yashiki 1987; Ikeda 1984).

In terms of topographical factors, the latrine sites of raccoon dogs were more often found on the ridge (Table 1). In some other carnivores, latrine sites occur at visually and olfactorily conspicuous sites where other individuals are likely to notice them in order to facilitate communication (e.g., golden jackals, Macdonald 1979; North American otters, Depue and David 2010; Swimley et al. 1998; common genets Genetta genetta, Espírito-santo et al. 2007). Slightly elevated areas such as ridges and rocky tops may be more easily detectable (Swimley et al. 1998). Since raccoon dogs use latrine sites for olfactory communication (Ikeda 1984; Yamamoto 1984), it is possible that raccoon dogs select visually and olfactorily conspicuous sites on the ridge to form latrine sites to facilitate odour dispersal.

The relationship between latrine sites and vegetation type showed that latrine sites tend to appear in broadleaf forests in autumn (Table 1). Previous studies have indicated that raccoon dogs primarily eat fruits in autumn as they accumulate fat for overwintering (Saeki 2008; Hirasawa et al 2006). In a previous study around Mt. Takadate, the same area as this study, it was reported that the occurrence frequency of fruit seeds in raccoon dog faeces was higher in autumn than in other seasons (Kato et al. 2000). Since broadleaf forests in the study area are important sites for raccoon dogs, which feed on a relatively higher quantity of fruits in autumn, it is possible that the raccoon dogs formed latrine sites near feeding sites (i.e., broadleaf forests) (Ikeda 1984). However, the results of the camera traps did not detect any effect of forest type on space use by raccoon dogs. This suggests that although raccoon dogs use broadleaf forests as feeding sites, the frequency of visits to broadleaf forests is not necessarily high. Raccoon dogs are opportunistic omnivores, have few constraints on food, and are not dependent on specific food resources (Hirasawa et al. 2006; Kaneko 2002; Sasaki and Kawabata 1994). In addition, the nightly movement range of raccoon dogs was 16.7 ha on average (Saeki et al. 2007). Given the ecology of raccoon dogs, it is possible that the raccoon dogs in the study area did not use the same feeding sites intensively; therefore, the frequency of visits to broadleaf forests was not significantly higher. Another possibility is that the camera traps were set across summer and autumn, and the data were influenced by differences in the space use of raccoon dogs between seasons (e.g., Saeki et al. 2007). Although it was difficult to separate the effect of seasons in this study due to the inconsistent frequency of photographs, the effects of vegetation types will become clearer as more surveys are accumulated.

In this study, we clarified the characteristics of latrine sites in raccoon dogs, which had not been evaluated quantitatively previously. Based on a comparison of the environmental selection of latrine sites and space use by raccoon dogs, we suggest that raccoon dogs selectively form latrine sites in convenient locations for communication and feeding. This result supports the importance of latrine sites to raccoon dogs. However, the number of occurrence locations and the occurrence frequency of raccoon dogs in our camera trapping might be insufficient for analysing the space use of raccoon dogs. Because the small number of occurrence data might be due to the fact that the survey sites were selected from a variety of environments in the survey area, the number of camera trap sites and/or the survey period for conducting similar surveys should be increased in the future. Furthermore, this study focused only on environmental factors at relatively large resolutions, and raccoon dog selectivity in microenvironments, such as ease of excretion and maintenance of the latrine sites, 
is unknown. By conducting surveys focusing on such microenvironments in the future, it will be possible to further understand the characteristics of the environments in which raccoon dogs form latrine sites.

\section{ACKNOWLEDGMENTS}

We thank the Shonai District Forest Office for permitting our field survey and the associates of Yamagata University for supporting our field survey.

\section{REFERENCES}

Akihito, T. Sako., M. Teduka, and S. Kawada. 2016. Long-term trends in food habits of the raccoon dog, Nyctereutes viverrinus, in the Imperial Palace, Tokyo. Bulletin of the National Museum of Nature andScience. Series A (Zoology) 42: 143-161.

Buesching, C. D., and N. Jordan. 2019. The Social Function of Latrines: A Hypothesis-Driven Research Approach. In Chemical Signals in Vertebrates 14, edited by Buesching, C. D., 94103. Cham: Springer Nature Switzerland AG. https://doi.org/10.1007/978-3-030-17616-7_8

Depue, J. E., and M. Ben-David. 2010. River otter latrine site selection in arid habitats of western Colorado, USA. Journal of Wildlife Management 74: 1763-1767. https://doi.org/10.2193/2008-065

Dormann, C. F., J. Elith, S. Bacher, C. Buchmann, G. Carl, G. Carré, J. R. G. Marquéz, B. Gruber, B. Lafourcade, P. J. Leitão, T. Münkemüller, C. McClean, P. E. Osborne, B. Reineking, B. Schröder, A. K. Skidmore, D. Zurell, and S. Lautenbach. 2013. Collinearity: a review of methods to deal with it and a simulation study evaluating their performance. Ecography 36: 27-46. https://doi.org/10.1111/j.1600-0587.2012.07348.x

Espírito-Santo, C., L. M. Rosalino, and M. Santos-Reis. 2007. Factors affecting the placement of common genet latrine sites in a Mediterranean landscape in Portugal. Journal of Mammalogy 88: 201-207. https://doi.org/10.1644/05-MAMM-A-343R3.1

Geospatial Information Authority of Japan. 2020. Foundation geographical data. https://fgd.gsi.go.jp/download/ menu.php (accessed on 21 May 2020).

Hirasawa, M., E. Kanda, and S. Takatsuki. 2006. Seasonal food habits of the raccoon dog at a western suburb of Tokyo. Mammal Study 31: 9-14. https://doi.org/10.3106/1348-6160 (2006) 31 [9:SFHOTR]2.0.CO;2

Ikeda, H. 1984. Raccoon dog scent marking by scats and its significance in social behaviour. Journal of Ethology 2: 77-84. https://doi.org/10.1007/BF02430571
Japan Meteorological Agency. 2021. Climatological normals (1981-2010). http://www.data.jma.go.jp/obd/stats/etrn/ view $/$ nml_amd_ym.php?prec_no $=35 \&$ block_no $=026$ $3 \&$ year $=\&$ month $=\&$ day $=\&$ view $=$ p 1 (accessed on 20 January 2021).

Kaneko, Y. 2002. The Raccoon Dog. In The Owl and the Raccoon Dog, Modern Natural History of Japan, edited by Hayashi, Y., and K. Takeuchi, 77-144. Tokyo: Iwanami Publ. Co [in Japanese].

Kato, S., Y. Nasu, and M. Hayashida. 2000. Seed dispersal and fruit morphology of endzoochorous plants dispersed by raccoon dogs, Nyctereutes procyonoides. Tohoku Journal of Forest Science 5: 9-15. [in Japanese with English summary]. https://doi.org/10.18982/tjfs.5.1_9

Kishimoto, M. 2000. Latrines of raccoon dogs. Iden 54: 86-88. [in Japanese].

Macdonald, D. W. 1979. The flexible social system of the golden jackal, Canis aureus. Behavioral Ecology and Sociobiology 5: 17-38. https://doi.org/10.1007/BF00302692

Ministry of the Environment. 2020. 1:25,000 scale vegetation map. http://gis.biodic.go.jp/webgis/index.html (accessed on 27 May 2020).

Miyata, I., T. Ogawa, T. Masuoka, and T. Matsumuro. 1989. Seed-dispersal behaviour of a raccoon dog, Nyctereutes procyonoides viverrinus Temminck, and the influence of fecal pile sites on seedlings in Chiku-shima Island, Shimane Peninsula. Studies of the San'in region (Natural Environment) 5: 109-120. [in Japanese with English summary].

National Institute of Advanced Industrial Science and Technology. 2021. LandBrowser. https://landbrowser. airc.aist.go.jp/landbrowser/index.html (accessed on 29 January 2021).

O’Brien, T. G., M. F. Kinnaird, and H. T. Wibisono. 2003. Crouching tigers, hidden prey: Sumatran tiger and prey populations in a tropical forest landscape. Animal Conservation 6: 131-139. https://doi.org/10.1017/S1367943003003172

Osawa, T., H. Mitsuhashi, Y. Uematsu, and A. Ushimaru. 2011. Bagging GLM: improved generalized linear model for the analysis of zero-inflated data. Ecological Informatics 6: 270-275. https://doi.org/10.1016/j.ecoinf.2011.05.003

Palomares, F. 1993. Faecal marking behaviour by freeranging Common genets Genett agenetta and Egyptian mongooses Herpestes ichneumon in southwestern Spain. Zeitschriftür Säugetierkunde 58: 225-231.

R Core Team. 2020. R: A Language and Environment for Statistical Computing. R Foundation for Statistical Computing: Vienna.

Saeki, M. 2008. Ecology of Animals Inhabiting a Satoyama Landscape - Raccoon Dogs. In Mammalogy in Japan II-Medium- and Large-sized Mammals and Primates, 
edited by Takatsuki, S., and J. Yamagiwa, 321-345. Tokyo: University of Tokyo Press [in Japanese].

Saeki, M. 2015. Nyctereutes procyonoides (Gray, 1834). In TheWild Mammals of Japan, Second Edition, edited by Odachi, S. D., Y. Ishibashi, M. A. Iwasa, D. Fukui, and T. Saitoh 224-225. Kyoto: Shoukadoh Book Sellers.

Saeki, M., P. J. Johnson, and D. W. Macdonald. 2007. Movements and habitat selection of raccoon dogs in a mosaic landscape. Journal of Mammalogy 88: 1098-1111. https://doi.org/10.1644/06-MAMM-A-208R1.1

Saito, M., and F. Koike. 2013. Distribution of wild mammal assemblages along an urban-rural-forest landscape gradient in warm-temperate East Asia. PLoS ONE 8: e65464. https://doi.org/10.1371/journal.pone.0065464

Saito, M. U., and F. Koike. 2015. Trait-dependent changes in assemblages of mid-sized and large mammals along an Asian urban gradient. Acta Oecologica 67: 34-39. https://doi.org/10.1016/j.actao.2015.06.002

Sasaki, H., and M. Kawabata. 1994. Food habits of the raccoon dog Nyctereutes procyonoides viverrinus in a mountainous area of Japan. The Journal of the Mammalogical Society of Japan 19: 1-8. https://doi.org/10.11238/jmammsocjapan.19.1

Sekiya, K. 1998. The Raccoon Dog in Shinshu. Matsumoto: Kyodo-shuppan-sha Publ. Inc. [in Japanese].
Swimley, T. J., T. L. Serfass, R. P. Brooks, and W. M. Tzilkowski. 1998. Predicting river otter latrine sites in Pennsylvania. Wildlife Society of Bulletin 26: 836-845. Yamamoto, I. 1984. Latrine utilization and faces recognition in the raccoon dog, Nyctereutes procyonoides. Journal of Ethology 2: 47-54. https://doi.org/10.1007/BF02348206

Yasiki, H. 1987. Ecological study on the raccoon dog, Nyctereutes procyonoides, in Shiga Heights. Bulletin of Institute of Nature Education in Shiga Heights 24: 43-53. [in Japanese with English summary].

Yoshida, K., and M. U. Saito. 2021. Behavioral response of wild mammals to pre-existing and artificial latrines of raccoon dogs in north-eastern Japan. Mammalia. https://doi.org/10.1515/mammalia-2020-0022

Watabe, R., and M. U. Saito. 2021a. Diel activity patterns of three sympatric medium-sized carnivores during winter and spring in a heavy snowfall area in north-eastern Japan. Mammal Study 46: 69-75. https://doi.org/10.3106/ms2020-0039

Watabe, R., and M. U. Saito. 2021b. Effects of vehicle-passing frequency on forest roads on the activity patterns of carnivores. Landscape and Ecological Engineering 17: 225-231. https://doi.org/10.1007/s11355-020-00434-7 